\title{
POLÍTICA(S) LINGUÍSTICA(S) E QUESTÕES DE PODER
}

\author{
Cristine Gorski SEVERO*
}

- RESUMO: O texto apresenta e discute os conceitos de poder e de política no campo de saber intitulado "Política Linguística". Para tanto, inicialmente apresenta e discute a heterogeneidade e complexidade do campo, discorrendo sobre os conceitos de Política e Planejamento Linguísticos. Em seguida, apresenta os trabalhos genealógicos do filósofo francês Michel Foucault acerca da relação entre poder, saber e política. Para fins de discussão, o artigo apresenta uma série de casos, tanto reais como possíveis, de aplicação e intervenção do campo de Política Linguística, com vistas tanto a discutir a noção de poder em conceitos e metodologias utilizadas pela área de saber, como a expandir o lócus de intervenção da disciplina a partir de possíveis contribuições de Michel Foucault sobre a dinâmica das relações de poder aplicada aos estudos das relações entre as línguas, as línguas e os sujeitos, as línguas e a tecnologia, e as línguas e uma dada geopolítica.

- PALAVRAS-CHAVE: Política Linguística. Planejamento linguístico. Poder. Saber. Línguas. Sujeitos. Internet.

\section{Introdução}

Este texto pretende discutir a dimensão política da área de saber intitulada "Política Linguística", a partir dos trabalhos de Michel Foucault sobre as relações entre poder, saber e política. Trata-se de explicitar, na medida do possível, as relações de poder inscritas em algumas práticas de descrição e intervenção na relação entre as línguas, as línguas e a tecnologia, as línguas e os sujeitos, e as línguas e uma dada geopolítica.

Esta disciplina é constituída, de forma geral, por dois eixos interligados: Política Linguística e Planejamento Linguístico. O primeiro eixo tem tradicionalmente se voltado para uma prática de caráter estatal-legislativo, debruçando-se, por exemplo, sobre a oficialização de línguas, a escolha de alfabeto para a representação gráfica de uma língua, a hierarquização formal das línguas (línguas de trabalho, oficiais, nacionais, por exemplo), entre outros. O segundo eixo tem focado a implementação das decisões sobre a língua através de estratégias (políticas), como as políticas educacionais, com vistas a influenciar o comportamento dos

* UFSC - Universidade Federal de Santa Catarina - Departamento de Língua e Literatura Vernáculas. Florianópolis - SC - Brasil. 88040-970 - crisgorski@gmail.com 
sujeitos em relação à aquisição e uso dos códigos linguísticos (COOPER, 1989). O conceito de planejamento linguístico foi utilizado inicialmente, em contexto acadêmico ocidental, por Einer Haugen (1961) em seu trabalho intitulado Planning in modern Norway, no qual analisou a situação da língua norueguesa na fase de independência da Noruega.

O "nascimento" da Política Linguística como campo científico disciplinar (EUA e Europa) se deu concomitante à emergência da Sociolinguística, ambas tendo como marco um evento organizado por William Bright na Universidade da Califórnia, em 1964, onde estiveram presentes nomes vinculados tanto à Política Linguística como à Sociolinguística, entre os quais Haugen, Labov, Gumperz, Hymes e Ferguson. Em 1968, coroando a consolidação do campo, houve a publicação do trabalho Language problems of developing nations, assinado por Fishman, Ferguson e Dasgupta (1968) (CALVET, 2007; BIANCO, 2004; MANLEY, 2008).

Essa fase inicial de configuração da Política Linguística no Ocidente como um campo disciplinar foi atravessada por esforços de sistematização e racionalização de um modelo aplicável aos estudos de descrição da relação entre as línguas e de seu funcionamento (político) nos limites do Estado. Tal esforço buscou fundar as regras de formação e legitimação da Política Linguística como campo de saber com estatuto científico, dado que "[...] uma disciplina se define por um domínio de objetos, um conjunto de métodos, um corpo de proposições consideradas verdadeiras, um jogo de regras e de definições, de técnicas e de instrumentos." (FOUCAULT, 1996, p.30). Exemplificando o processo de formação da Política Linguística como disciplina, os métodos de sistematização da relação entre as línguas incluíam classificações hierárquicas das línguas (vernácula, padrão, clássica, crioula e pidgin), das suas funções (língua de ensino, oficial, internacional, veicular, religião e gregária), de seus atributos, dos seus diferentes níveis de favorecimento/desfavorecimento (escala GIDS de Fishman), entre outros (CALVET, 2007; BIANCO, 2004).

Os trabalhos pioneiros que se devotaram à delimitação deste campo de saber mantiveram firme o compromisso com a racionalidade científica, com algumas poucas exceções:

Corroborando o clima intelectual de preponderante otimismo científico, apenas uma minoria dos pioneiros da Política e Planejamento linguísticos eram céticos sobre quaisquer limites postos aos protocolos técnicos e muitos imaginaram banir a subjetividade e os interesses das suas considerações ${ }^{1}$ (BIANCO, 2004, p.740).

"In keeping with the prevailing intellectual climate of scientific optimism, only a minority of LPP pioneers were skeptical about any limits to technical protocols and many imagined banishing subjectivity and interests from consideration". As traduções ao longo do artigo são de minha responsabilidade." 
A crítica ao positivismo e empirismo presentes na Política Linguística como disciplina pode ser também evidenciada na seguinte colocação feita por Rajagopalan (2005, p.138) sobre a gestão do tema pelos linguistas:

É um grande equívoco pensar que a política linguística deve pautar-se pelas descobertas e afirmações da linguística ou qualquer outra ciência formal. Nenhuma ciência que aborde seu objeto de estudo de maneira idealizada e desvinculada dos anseios do dia-a-dia pode-se dar ao luxo de se autoproclamar dona do saber soberano quando se trata de assuntos práticas relacionados ao seu objeto de estudo [...].

O ceticismo e a resistência aos modelos científicos e positivistas de estudo da relação (política) entre as línguas se evidenciam em algumas abordagens modernas que se debruçam sobre o tema, conforme será visto adiante.

A seguir, apresentam-se e discutem-se os conceitos de política linguística e de planejamento linguístico em sua complexidade com vistas a uma reflexão, a partir dos trabalhos de Michel Foucault, sobre a dimensão política das práticas e enfoques do campo disciplinar da "Política Linguística".

\section{A Política Linguística como um campo multifacetado}

O conceito de política linguística é complexo e polissêmico. A heterogeneidade deste campo de saber varia entre os seus alvos e níveis de intervenção, além de sua relação com o planejamento linguístico, em que este ora é tido como mera aplicação da política linguística, ora é tido como o seu coração, gerando um desequilíbrio entre as prioridades teórico-metodológicas adotadas. Além disso, em alguns casos, priorizam-se aspectos técnicos em detrimento de políticos na atuação sobre questões linguísticas, prática que tem sido alvo de críticas reiteradas, como o posicionamento de Rajagopalan (2005) citado anteriormente. A heterogeneidade do campo ocorre também em relação aos diferentes contextos sócio-políticos de constituição da disciplina: as tradições americana, europeia e soviético-russa, por exemplo, não compartilham as mesmas prioridades e enfoques teórico-metodológicos, o que pode estar vinculado tanto às regras (históricas) de configuração do campo disciplinar, como à realidade política das línguas nesses contextos:

[...] os primeiros teóricos - norte-americanos - da política e do planejamento linguísticos [...] tendiam a negligenciar o aspecto social da intervenção planejadora sobre as línguas. Diante deles, os linguistas europeus [...] insistiram na existência de conflitos linguísticos [...] Mas sua situação os levou a misturar assuntos e a passar, lentamente, do teórico ao militante. (CALVET, 2007, p.35-36). 
Um outro traço indicador da heterogeneidade do campo da Política Linguística abrange tanto os contextos (nacionais, pós-coloniais) estudados, como os níveis macro, meso e micro de intervenção. É o que se percebe, por exemplo, em estudos de caso em torno da especificidade da política linguística em contextos pós-coloniais (CANAGARAJAH, 2005; HILL, 2010; SEVERO, 2011a, 2011b); ou no desmembramento da intervenção da política linguística em três eixos: oficial, educacional e geral, estando o primeiro vinculado às decisões sobre o estatuto oficial das línguas, o segundo ao ensino das línguas e o terceiro às línguas da comunicação de massa, dos negócios e das relações com os estrangeiros (NOSS, 1971 apud GADELII, 1999). Diferentemente desse desmembramento do nível macro de intervenção da política linguística, Spolsky (2004 apud BONACINAPUGH, 2012) propõe uma aproximação entre as políticas e as práticas locais, indicando os seguintes elementos como constitutivos dos diferentes níveis da política linguística: a gestão das línguas, que lida com uma política explícita e oficializada de uso das línguas; as crenças e ideologias linguísticas, que afetam os usos linguísticos; e as práticas linguísticas, que se vinculam aos padrões interacionais. Neste caso, as fronteiras entre política e planejamento linguísticos se tornam mais tênues. Comparando as propostas de Noss e Spolsky, notam-se, de início, duas dimensões políticas em jogo: uma que vincula a dimensão política mais fortemente às atuações institucionais, verticais, oficiais e jurídicas; e outra que prioriza uma política vinculada às crenças e práticas locais, às ideologias e às motivações que levam os sujeitos a fazerem uma ou outra opção linguística. Essas duas perspectivas de poder, uma vertical e outra horizontal, serão retomadas na seção seguinte.

Assim como a política linguística, o conceito de planejamento linguístico também não é uniforme e homogêneo. Para ilustrar a complexidade desse conceito, considera-se o trabalho de Einer Haugen (1966) intitulado Language conflict and language planning: the case of modern Norwegian. O autor sistematizou quatro níveis envolvidos no planejamento linguístico da língua norueguesa: seleção da norma, codificação/padronização da norma, implementação/aceitação e elaboração/modernização da língua pela disseminação de novos termos. Esses níveis foram posteriormente desdobrados por outros estudiosos em: práticas de planejamento de corpus (codificação, elaboração de alfabetos, gramatização, sistematização do léxico, manuais literários, entre outros), planejamento do status (designações e usos da língua pautadas por leis e decretos), planejamento das formas de aquisição (políticas de ensino e aprendizagem das línguas), planejamento de usos (políticas de divulgação e uso das línguas) e planejamento de prestígio (avaliação dos usos linguísticos). Os dois primeiros planejamentos foram tratados por Kloss (1967), o terceiro foi adicionado por Cooper (1989) e o último foi proposto por Baker (2003) (MANLEY, 2008; BIANCO, 2004; COOPER, 1989). 
O papel do planejamento de prestígio, embora reconhecido, não é tomado como uma questão central no campo do Planejamento Linguístico:

É compreensível que as questões de planejamento linguístico se relacionem a julgamentos de valor. Contudo, uma teoria do planejamento linguístico não precisa, necessariamente, enquanto teoria, assumir uma posição de juízo de valor. ${ }^{2}$ (COBARRUBIAS; FISHMAN, 1983, p.6).

Indaga-se em que medida a marginalização deste tema no interior do campo restringe reflexões sobre a maneira pela qual a seleção e a hierarquização das línguas e dos usos linguísticos são afetadas por dimensões ideológicas evidenciáveis tanto nas avaliações valorativas dos falantes em relação à língua, como nas práticas dos próprios pesquisadores. Acredita-se que esta dimensão está diretamente vinculada à propagação/circulação das línguas e dos usos linguísticos, uma vez que as diferentes valorações influem diretamente nos usos.

Além daqueles cinco planejamentos, Bianco (2004) sugere a incorporação de um sexto: o planejamento discursivo, encarregado de lidar com o trabalho ideológico das instituições, mídia, discursos de autoridade, entre outros, na produção e circulação de crenças sobre as línguas, o que afeta diretamente os usos linguísticos. Este nível, contudo, parece se aproximar do planejamento de prestígio, sendo que o autor não esclarece a diferença entre ambos.

Ainda para problematizar a heterogeneidade dos conceitos de política e planejamento linguísticos, mencionam-se os estudos de Cooper (1989) sobre quatro casos envolvendo questões de língua: a fundação da Academia Francesa, em 1635, por Richelieu, a revitalização da língua hebraica na Palestina a partir do século XIX, o movimento feminista americano da década de 1960, e a campanha de alfabetização em massa na Etiópia conduzida por estudantes universitários em 1974. O autor expande o entendimento clássico dos conceitos para incluir maneiras de resolução de problemas, em âmbito macro e/ou local, que envolvam questões linguísticas de natureza política. Cooper (1989), ao revisar doze conceitos de política linguística, identificou uma questão comum a todos eles: "Quem planeja o que para quem e como?". Subentende-se daí que há, pelo menos, quatro instâncias envolvidas em políticas e planejamento linguísticos: a instância legisladora/regulamentadora vinculada, tradicionalmente, embora não unicamente, aos órgãos governamentais; o campo de intervenção que vai da documentação e descrição do sistema linguístico (planejamento de corpus) à distribuição, designação e normatização das línguas e dos usos linguísticos (planejamento de status); o público-alvo e os efeitos da intervenção linguística;

"It is understandable that language-planning issues relate to value judgements. However, a theory of language planning does not necessarily, qua theory, have to take a stand of value judgement." 
e os procedimentos implicados na execução da política linguística com vistas, por exemplo, ao aumento do número de falantes (planejamento da aquisição).

Destrinchando os participantes (quem faz e para quem), o objeto (o que) e as metodologias (como) envolvidos na política e no planejamento linguísticos, tem-se, de forma geral:

(i) Quem e para quem - as instâncias envolvidas no planejamento das políticas linguísticas são diversas, como: os poderes executivo e legislativo, as esferas jurídica, administrativa, de negócios, educacionais, midiática, as academias literárias, as organizações civis, entre outros. Tradicionalmente, os atores envolvidos na gestão de políticas linguísticas se vinculam, direta ou indiretamente, às esferas governamentais como representantes de um discurso oficial. Contudo, uma abordagem mais crítica tem defendido a incorporação de crenças e ideologias como variáveis diretamente envolvidas na prática de política linguística; nesta perspectiva, "[...] política e planejamento linguísticos são processos ideológicos que contribuem para a manutenção de relações de poder desiguais entre grupos linguísticos majoritários e minoritários." ${ }^{3}$ (BONACINA-PUGH, 2012, p.216). Ou seja, trata-se de considerar o papel da dimensão ideológica e discursiva da política e planejamento linguísticos na construção e manutenção de hierarquias e do status quo.

Além dos participantes oficiais e das crenças e atitudes dos sujeitos, há ainda uma terceira via, embora não excludente das demais, que propõe incorporar as práticas como alvo das políticas linguísticas. Neste caso, trata-se de averiguar a maneira pela qual uma dada política linguística pode ser construída em práticas interacionais (BONACINA-PUGH, 2012) ou, em outros termos, de que maneira certos padrões linguísticos são reiterados em diferentes práticas interacionais, que não são espontâneas, mas obedecem a regras (implícitas) que atuam tanto regulando como inovando o comportamento linguístico.

(ii) $\mathbf{O}$ que - o objeto privilegiado de intervenção da política e planejamento linguísticos envolve o planejamento do corpus, que inclui as seguintes ações: criação, reforma e padronização do sistema ortográfico; especificação de pronúncias, escolha da grafia, expansão vocabular e terminológica; alterações na estrutura gramatical; criação de registros simplificados para fins específicos; cultivo e valorização dos diferentes estilos e gêneros; produção de cartilhas, manuais e livros didáticos voltados para a alfabetização; tradução de obras variadas; produção de dicionários e gramáticas; produção de textos escritos vinculados a diferentes gêneros; e criação de órgãos especializados em questões linguísticas (GADELII, 1999).

"[...] language policy and planning are ideological processes which contribute to maintaining unequal power relationships between majority and minority language groups." 
Já as intervenções no status/funções e no prestígio das línguas, por não receberem dos linguistas a mesma atenção que o planejamento de corpus, são menos sistematizadas (FERGUSON, 1983). Considerando que "[...] uma língua é investida de certo status comunicativo em virtude de regras convencionais de uso lingüístico."“ (COBARRUBIAS; FISHMAN, 1983, p.49), a tarefa dos planejamentos de status e de prestígio seria de compreender e intervir nessas regras de designação e funcionamento das línguas que as categorizam como língua nacional, oficial, de trabalho, co-oficial, oficial no âmbito municipal, língua de ensino (nos diferentes níveis escolares), língua com funções jurídicas, línguas artísticas, religiosas, científicas, tecnológicas, línguas de comunicação de massa, línguas literárias, línguas proibidas, etc. A natureza das regras que definem o status e o prestígio das línguas não é neutra/científica, mas política, uma vez que os processos de designação e de circulação das línguas instauram e conservam hierarquias, refletem/constroem desigualdades linguísticas e sociais, aproximam ou distanciam grupos, favorecem certas comunidades linguísticas em detrimento de outras, instauram práticas legitimadoras de certas línguas e de apagamento de outras, etc. Não é por acaso que os trabalhos na área de planejamento de status sinalizam que "[...] decisões do planejamento de status se ajustam às ideologias da elite de poder ou respondem a ideologias conflitantes entre aqueles apoiados pela elite de poder e aqueles do outro grupo constituinte." ${ }^{5}$ (COBARRUBIAS; FISHMAN, 1983, p.62).

Ainda sobre o planejamento do status, Hill (2010), considerando a realidade multilíngue da África do Sul, problematiza a separação do conceito de status da noção de língua. Segundo o autor, o planejamento de status se tornou fundamental para se compreender de que maneira, a despeito de uma política que oficializa onze línguas na África do Sul, a circulação das demais línguas oficiais (com exceção do Inglês) não sofreu modificações, tendo, inclusive, " [...] diminuído em certos domínios formais - notadamente no ensino formal de línguas." 6 (HILL, 2010, p.43). A única exceção apontada seria a língua isiZulu presente em alguns jornais. Ironicamente, segundo o autor, a promoção dos discursos sobre multilinguismo na África do Sul foi acompanhada de um aumento da circulação do inglês e uma diminuição da efetiva circulação das línguas locais. Esta discussão será retomada na seção seguinte.

(iii) Como - as formas de estudo, análise e aplicação da política e planejamento linguísticos variam, conforme visto, segundo o nível de intervenção (macro, meso, micro), o enfoque (linguístico, linguístico-discursivo, discursivo), a finalidade

\footnotetext{
4 "[... ] a language is vested with a certain communicative status by virtue of conventional rules of language use."

5 "[...] status planning decisions conform to ideologies of power elite or respond to conflicting ideologies between those upheld by the power elite and those of other constituent group."

6 " ... ] declined in some formal domains - and notably in formal language teaching."
} 
(planejamento do corpus, da função, do prestígio, etc.) e os participantes envolvidos (esferas oficiais, atitudes e crenças dos sujeitos ou práticas de interação). Impossível, dada a abrangência de possibilidades de intervenção, sistematizar as metodologias utilizadas e aplicadas em política e planejamento linguísticos, já que cada vez mais os estudos da área têm se debruçado sobre temas complexos, como situações de políticas linguísticas em sociedades pós-coloniais, multilinguismo na internet, relação entre línguas e tecnologias, multilinguismo em regiões de fronteira e em situações de migração e diáspora, entre tantos outros.

A seguir, a partir dos trabalhos de Foucault, discorre-se sobre as noções de poder e de política implicadas na política e no planejamento linguísticos. Toma-se como base ilustrativa para a discussão uma série de casos de intervenção deste campo de saber. A partir da perspectiva foucaultiana sobre o funcionamento do poder, são propostas algumas outras possibilidades de intervenção e de compreensão da relação entre as línguas, as línguas e o Estado, as línguas e a tecnologia, e as línguas e os sujeitos, temas que perpassam os interesses da política e do planejamento linguísticos.

\section{Sobre o poder na Política e no Planejamento Linguísticos}

Os trabalhos do filósofo francês Michel Foucault (1995) focalizam, de forma geral, três eixos interligados: verdade/saber, poder e sujeito. Acredita-se que suas reflexões detalhadas e minuciosas sobre o funcionamento do poder tanto em relação aos discursos/saberes, como em relação ao funcionamento das sociedades modernas, podem ser tomadas como chave de leitura e reflexão da dinâmica do poder no contexto teórico e aplicado da política e do planejamento linguísticos. Para tanto, serão apresentadas a seguir, de forma sucinta, algumas características do funcionamento do poder segundo Foucault. Neste viés, todo discurso é político, na medida em que produz efeitos variados sobre a realidade, os sujeitos, as relações, os comportamentos, as línguas, entre outros. Não se trata, com a discussão a seguir, apenas de explicitar a natureza política e o funcionamento do poder nas práticas e teorias que constituem a política e o planejamento linguísticos, mas se trata de pensar a maneira pela qual a abordagem foucaultiana do poder pode, inclusive, ser útil e produtiva para as reflexões e intervenções da área de Política Linguística.

Em seu curso intitulado "Soberania e Disciplina" (FOUCAULT, 1999a) e na obra "História da Sexualidade: a vontade de saber" (FOUCAULT, 1999b), Foucault sistematiza as características do poder nas sociedades modernas. De forma geral, o filósofo defende que é impossível viver fora das malhas do poder, mesmo porque o poder não é um objeto que se detenha, não se concentra nas mãos de uns em detrimento de outros, não opera apenas vertical e hierarquicamente e não se 
vincula apenas às instituições. As relações de poder são múltiplas, difusas, fluidas, dinâmicas e vinculadas, diretamente, à produção, circulação e recepção dos discursos. Com isso, a seguir apresentam-se e discutem-se, esquematicamente na forma de seis itens, as características da dinâmica política do poder aplicadas aos estudos e práticas em política e planejamento linguísticos:

(i) O poder não se restringe ao poder soberano (jurídico ou Estado) central, mas opera nas extremidades, nas ramificações, em instituições e práticas locais e regionais. Em termos de políticas linguísticas, pode-se aventar que a análise do poder na relação entre as línguas, as línguas e os sujeitos, e as línguas e o Estado pode ser feita a partir de um enfoque local. É o que se nota com algumas propostas de estudo de políticas linguísticas focalizando práticas interacionais, instituições locais (famílias, comunidades religiosas), grupos sociais, entre outros: "Enquanto a literatura de planejamento linguístico tem focado principalmente o nível macro, é importante compreender que política e planejamento linguísticos também operam no nível micro."7 (KAPLAN; BALDAUF, 1997, p.1). A análise do funcionamento de uma política linguística não jurídica ou estatal possibilita a compreensão da maneira pela qual os significados sociais vinculados às escolhas linguísticas são construídos e reforçados localmente, atuando, por exemplo, na construção e manutenção de certas identidades. O estudo local da dinâmica do poder em relação às línguas pode tornar-se particularmente revelador quando confrontado aos estudos macro, que focalizam as instâncias regulamentadoras estatais. Neste confronto, como se dá a relação entre o micro e o macro? Não se trata, nesse caso, de considerar o micro como efeito do macro, mas de averiguar como ambos se relacionam produzindo efeitos mútuos.

A título de ilustração, menciona-se o trabalho de planejamento linguístico encabeçado pelo Departamento de Governo Local e Provincial (Department of Provincial and Local Government, DPLG) da África do Sul e conduzido pelos municípios - terceiro nível do governo - em busca de uma valoração positiva do uso das línguas locais em contexto público, envolvendo tanto agentes governamentais municipais, como representantes da comunidade civil local (WEBB, 2009). Trata-se de um tipo de planejamento centrado na comunidade local, priorizando " [...] o envolvimento ativo da comunidade, especialmente de pessoas pobres, de forma a melhorar a qualidade dos planos e serviços, ampliar o controle comunitário sobre o desenvolvimento e empoderar as comunidades para que elas ajam."8 (Relatório do DPLG apudWEBB, 2009, p.3). Tal iniciativa de planejamento linguístico na África do Sul visou a lidar com a ineficácia da abordagem tradicional

\footnotetext{
7 "Whereas the language planning literature has focused mainly on the macro level, it is important to understand that language policy and planning operates at the micro level as well."

8 " [...] the active involvement of the community, especially poor people, so as to improve the quality of plans and services, extend community control over development and empower communities so that they take action."
} 
(de cima para baixo) de planejamento linguístico para uma realidade multilíngue, em que as línguas africanas não têm o mesmo status (econômico, político, cultural) que o inglês. Nesta política linguística ascendente (bottom-up), dois requisitos foram tomados como necessários para a sua efetivação (WEBB, 2009): que os representantes locais fossem legitimados pela comunidade e, por isso mesmo, pudessem falar por ela; que as organizações e os representantes locais fossem munidos de conhecimento e capacidade para lidar com a questão, neste caso, uma política local das línguas. A intervenção sobre a promoção e circulação das línguas locais implica a mobilização das mídias de massa (programas de rádio e TV locais), de mídias impressas (revistas, jornais e boletins locais) e de mídias digitais (internet), de forma que elas se tornem instrumentos tanto de veiculação como de legitimação das línguas locais. Além disso, há a promoção das línguas em contexto educacional, com o investimento em educação bi-multilingue o que implica, por exemplo, a elaboração de material didático específico, entre outros.

Ainda no âmbito governamental de nível micro, no Brasil, algumas iniciativas municipais têm cooficializado línguas de grupos e comunidade locais. É o caso, por exemplo, da oficialização da língua indígena guarani nos municípios de São Gabriel da Cachoeira/AM (2002), juntamente com outras três línguas indígenas - nheengatu, tukano e baniwa; e de Tacuru/MS (2010), com o reconhecimento formal também das variedades do guarani - kaiowá, ñandeva e mbya. Tal iniciativa oficial deveria implicar o uso público da língua, juntamente com o português, em contextos como o oferecimento de serviços públicos, a escola, o meio jurídico, a esfera política, os meios de comunicação, entre outros. No âmbito das línguas de imigrantes, houve a cooficialização da língua pomerana no município de Santa Maria de Jetibá/ES (2009), que juridicamente previu o uso da língua em documentação pública, campanhas publicitárias e institucionais, entre outros; e, em 2010, o município de Antônio Carlos/SC cooficializou a língua hunsrückisch, obrigando o ensino da língua em escolas municipais ${ }^{9}$. Evidentemente, embora resultantes de uma política oficial local, tais iniciativas exigem planejamentos locais efetivos de circulação e validação dessas línguas em contexto público, tema que será discutido a seguir.

(ii) O poder, segundo Foucault, não se restringe à intenção ou ação de alguns sujeitos sobre outros. Não se trata de buscar uma origem, um início ou um dono do poder, mas de rastrear os seus efeitos e percursos. Nenhum sujeito é detentor do poder, mas é o seu efeito, um lugar de passagem e de incidência do poder. Ou seja, trata-se menos da origem do poder e mais do seu objeto, alvo e ponto de aplicação, com vistas a averiguar de que maneira o poder opera tanto submetendo, dominando e assujeitando, como produzindo, incitando e

9 Informações sobre a legislação municipal dessas cooficializações estão disponíveis no site do Instituto de Investigação e Desenvolvimento em Políticas Linguísticas (IPOL). Disponível em: <http://www.ipol.org.br>. 
promovendo a circulação. Neste caso, as instâncias legisladoras e reguladoras não são tomadas como o a priori do poder, mas como um nó em uma rede mais complexa e difusa, cujo funcionamento é percebido pelos efeitos que o poder produz. Tais efeitos incluem: promoção de discursos com estatuto de verdade, produção de subjetividades, de crenças, de comportamentos, entre outros. A.ssim, na ótica de uma política linguística de inspiração foucaultiana, não se trata de focar apenas a concepção de que "[...] o planejamento linguístico é uma tentativa de alguém de modificar o comportamento linguístico de alguma comunidade por algum motivo." ${ }^{10}$ (KAPLAN; BALDAUF, 1997, p.3), mas de averiguar, em uma rede de poder mais ampla, de que maneira os discursos oficiais, ou os "detentores" do poder e das decisões oficiais (os "dominadores") são afetados por uma mesma dinâmica de poder que constitui também os "dominados".

(iii) Vinculado aos itens anteriores, o poder não pode ser visto como um bloco homogêneo e único, localizável e imposto por uns sobre outros, uma vez que "o poder funciona e se exerce em rede" (FOUCAULT, 1999a, p.103). Isso implica uma metodologia de trabalho que permita rastrear e considerar os vários elos e nós desta rede que circula entre o macro, o meso e o micro, produzindo uma série de efeitos. Para exemplificar este funcionamento em rede, pode-se mencionar a apropriação da disciplinarização gramatical de uma política linguística jesuítica (CÂMARA JUNIOR, 1965 apud BARROS, 2003) pelos aparelhos do Estado e pelas academias, em que a prática de produção de saber no interior de uma esfera religiosa é apropriada pelas esferas política e científica. Uma consideração pode ser feita em relação aos catecismos escritos em língua tupi: a política linguística jesuítica não apenas gramatizou o tupi, como também fez circular nesta língua, de tradição oral, textos católicos, conferindo uma colonização discursiva pela língua do outro. Nota-se que este modelo de investimento e apropriação das línguas ainda persiste quando, paralelamente à defesa de um multilinguismo, tem-se uma homogeneização discursiva. Talvez seja tal homogeneização discursiva que, conforme já visto, leva Hill (2010) a diagnosticar na África do Sul, um país com onze línguas oficiais, uma desproporção na circulação das línguas em contexto público, o que se explica pelo status político, econômico e acadêmico conferido à língua inglesa:

[...] ironicamente, o compromisso oficial com o multilinguismo e, associado a isto, o desenvolvimento de um discurso doméstico sobre o planejamento linguístico multilíngue coincidiu com o crescimento de facto do status do inglês. ${ }^{11}$ (HILL, 2010, p.43).

10 "....] language planning is an attempt by someone to modify the linguistic behaviour of some community for some reason."

11 "[...] ironically, the official commitment to multilingualism and the associated development of a domestic discourse on multilingual language planning has coincided with the de facto growth in the status of English." 
Tal diagnóstico tem feito com que linguistas sul-africanos se debruçassem sobre o planejamento do status das línguas locais, corroborando a reflexão sobre a (não) aplicabilidade de conceitos e metodologias da política linguística americana e europeia em contexto africano.

Nesta direção, Makoni e Meinhof (2006) questionam o próprio conceito de língua em África, afirmando, por exemplo, que a relação entre língua e identidade compartilhada - tão cara aos estudos de política linguística e sociolinguística passou a existir naquele continente a partir da colonização, do cristianismo e do nacionalismo: "[...] as línguas (e não a língua) e as metalinguagens emergiram literalmente como parte do projeto colonial cristão." (MAKONI; MEINHOF, 2006, p.197). Os missionários, tanto da África como nas Américas, sobrepuseram as tarefas políticas de evangelização e de produção de saberes sobre as línguas locais (gramatização), embora o próprio conceito de língua fosse uma construção, uma vez que a categorização das línguas é um processo ocidental de sua representação. Assim, as línguas não estavam já lá prontas para serem descobertas, mas foram construídas, fragmentadas e isoladas social e linguisticamente (MAKONI; MEINHOF, 2006). Dessa forma, os autores defendem uma política linguística escolar que incorpore a consciência sociolinguística como parte do currículo, ou que, pelo menos, os materiais pedagógicos incorporem textos autênticos em línguas variadas, estremecendo tanto a pressão da aprendizagem de uma variante-padrão, como a necessidade de padronização e delimitação das línguas africanas. Esta visão é reforçada pela ideia de que os limites que definem as línguas africanas são muitas vezes fruto de um trabalho linguístico-científico desconectado da realidade social e funcional, o que se evidencia no fato de sujeitos se comunicarem em línguas estruturalmente "diferentes", mas considerarem que falam a "mesma" língua, ou o contrário, quando estruturalmente duas línguas são tomadas como apenas um sistema, embora os falantes considerem que se trata de duas línguas. Ademais, a prática educacional africana não ocidental teria outras prioridades, como a formação moral do sujeito, ao invés do ensino e sistematização de uma variedade padrão (MAKONI; MEINHOF, 2006). É por tais motivos que os autores defendem uma Linguística Aplicada local que considere a realidade e as pessoas envolvidas na dinâmica linguística: "Ignorar as percepções dos usuários provavelmente produzirá resultados negativos quando os linguistas aplicados intervierem em muitos contextos sociais." (MAKONI; MEINHOF, 2006, p.209).

Ainda sobre a dinâmica de uma política linguística em rede, a oficialização em nível federal ou municipal - não implica, necessariamente, sucesso em relação à circulação e legitimação das línguas. Há uma série de variáveis que atuam nesta dinâmica e que pouco são consideradas ou avaliadas. Para exemplificar, alguns fenômenos (ideológicos, políticos, econômicos) podem ser elencados como obstáculos à circulação efetiva das línguas em contexto público: falta de compreensão da importância, pelos legisladores, da circulação efetiva das 
línguas minoritárias; mitos compartilhados sobre o multilinguismo, como a ideia de que efetivação de uma política multilíngue seria excessivamente custosa; o desconhecimento da história do funcionamento das línguas em uma dada localidade e da maneira como certas línguas assumem significado social de prestígio em detrimento de outras; e interesses políticos e econômicos de grupos locais em detrimento do interesse público (WEBB, 2009). Sobre este último item, na globalização, os bens culturais (entre eles, a língua) assumem, pela sua possibilidade de circulação ampla, um valor econômico agregado, o que acaba sobrepondo os interesses comerciais aos interesses públicos: "Relativismo linguístico e cultural é uma mercadoria popular na comunidade empresarial. Pesquisar variabilidade linguística e cultural e vender os resultados de tal pesquisa é um negócio em florescimento." ${ }^{2}$ (DOR, 2004, p.102). Nessa perspectiva, o multilinguismo passa a assumir um valor econômico que, paradoxalmente, esvazia a sua força de efetivamente promover a existência dialógica da pluralidade no espaço público, pois passa a funcionar em prol dos interesses de grupos privilegiados (ARENDT, 2005). Tal esvaziamento se evidencia, por exemplo, tanto no fracasso de uma série de políticas linguísticas (top-down) em defesa do multilinguismo, como no interesse de empresas comerciais pela produção de conhecimentos sobre as línguas minoritárias. É o que se observa pelo investimento financeiro da Fundação Volkswagen no projeto "Gramática Multi-Mídia baseada no discurso natural, no exemplo do Awetí", vinculado ao Museu do Índio, uma iniciativa do Ministério de Ciência eTecnologia do Brasil ${ }^{13}$, que tem como meta, junto com o Museu Nacional, a construção de acervo digital de línguas indígenas.

Uma outra variável a ser considerada na rede de elementos que afetam a política e o planejamento linguísticos, sendo muitas vezes tomada como um obstáculo "neutro" à concretização da circulação das línguas, é a tecnologia. Para exemplificar: no município de São Gabriel da Cachoeira, já mencionado, um indígena não pôde registrar seu filho com o nome indígena porque não há no teclado do computador uma grafia para um som tuiuca, aspirado entre "u" e "i" e representado como um u cortado ${ }^{14}$. Os teclados com representações gráficas restritas é um exemplo de como os designs de hardware e software operam também como um elemento na rede horizontal de variáveis que afetam uma política linguística. Evidentemente, a indústria tecnológica não é neutra, mas opera

12 "Linguistic and cultural relativism is a popular commodity within the business community. Researching linguistic and cultural variability, and selling the results of this research, is a flourishing business."

13 Informações disponíveis no site do Ministério de Ciência e Tecnologia, patrocinador do Museu Paraense Emílio Goeldi ao qual se vinculam as iniciativas de documentação das Línguas Indígenas da Amazônia: Disponível em: <http://saturno.museu-goeldi.br/lingmpeg>. Acesso em: 27 jul. 2012.

14 Este dado foi utilizado como exemplo para ilustrar o atraso da efetivação de uma política de cooficalização das línguas indígenas no município de São Gabriel da Cachoeira (AM) em notícia publicada pelo jornal Folha de São Paulo (FolhaOnLine, 07/07/2009), sete anos após a lei municipal. Disponível em: <http://www1.folha.uol.com. br/folha/treinamento/novoemfolha47/ult10115u592115.shtml>. Acesso em: 27 jul. 2012 
em função de interesses econômicos e políticos: "[...] a indústria computacional hoje tem um controle sem precedentes sobre as línguas em quase todos os níveis." 15 (DOR, 2004, p.114).

Ainda no âmbito dos efeitos das restrições tecnológicas sobre as línguas, os serviços e formas de comunicação que se apoiam em mensagens textuais curtas - tipicamente encontradas em celulares e formas de interação mediadas pelo computador - produzem a emergência de um fenômeno linguístico híbrido denominado neografia (neography), caracterizado por uma representação ortográfica da língua de forma não convencional. Em contexto francês, linguisticamente bastante conservador, Danet e Herring (2007) identificaram algumas variações linguísticas características da neografia que, utilizadas por jovens e crianças, extrapolam os limites tecnológicos e eletrônicos e passam a ser usadas em outros contextos, como o escolar. Tal uso não é amplamente aceito e validado, inclusive no meio digital em que alguns newsgroups franceses condenam o seu uso (DANET; HERRING, 2007). Algumas dessas variações incluem: queda dos acentos; substituição de qu por $k$, incorporando o fonema à grafia; encurtamentos de palavras e frases; supressão ou duplicação de vogais; substituição de sílabas por numerais; redução de sílabas ( $C$ ao invés de $C$ 'est); uso de rebus e logogramas; entre outros. Neste caso, trata-se de considerar para fins de políticas linguísticas os efeitos das restrições tecnológicas sobre a grafia e circulação das línguas. Reitera-se que tais efeitos não são neutros, mas politicamente saturados, o que evidencia a natureza também política da tecnologia (BIJKER, 2006).

Ainda no âmbito tecnológico, sobre a intensificação da circulação de certas línguas pela internet, rompendo com os limites e fronteiras territoriais, tem-se que: se, por um lado, a partir do século XVI, uma certa política linguística foi mobilizada na constituição de um Estado-nação para garantir a sua unidade e seus limites territoriais, por outro lado, com as novas mídias digitais, há uma desestabilização cada vez maior desses limites, o que se evidencia em fenômenos de contato entre as línguas possibilitado por novas comunidades virtuais no meio digital. Para ilustrar as comunidades virtuais multilíngues, o site FanFiction.net - maior site de postagem de fanfics, ficções produzidas por fãs - abriga textos em mais de 30 idiomas, alguns deles de base não latina e que são lidos e comentados por fãs que compartilham o interesse comum por uma mesma obra, música, filme, jogo, etc. As comunidades virtuais, além de compartilharem diversas línguas, também podem utilizar um tipo de linguagem (digital) comum a diferentes culturas. É o caso de certos símbolos que passam a ser usados internacionalmente, como @, 2, 4, msg, 2mrw, etc., cujos significados em inglês são respectivamente at, to, for, message e tomorrow.

15 "[... the computer industry now has unprecedented control over languages at almost every level." 
Em uma pesquisa sobre a relação entre os usos de um padrão de linguagem (digital) global e recursos linguísticos locais por jovens belgas, Blommaert (2012) identificou uma hibridização entre os dois padrões, fenômeno que o autor chamou de "englobalization" do padrão local e "deglobalization" do padrão geral. Evidentemente, tais contatos linguísticos não produzem efeitos ilimitados sobre as línguas, pois há também regras que gerenciam a formação e o uso de tais hibridismos linguísticos. Assim, usar uma língua ou outra na internet não implica, necessariamente, o vínculo a uma identidade nacional territorial, mas ilustra uma nova dinâmica espacial (política, cultural, econômica) sendo produzida pela distribuição e circulação das línguas na internet. Trata-se de uma mudança, portanto, na economia política das línguas (DOR, 2004), um outro campo/espaço de atuação das políticas linguísticas que tem a tecnologia como variável política atuante sobre a dinâmica da relação entre línguas, línguas e sujeitos, e línguas e geopolítica.

(iv) O estudo da dinâmica do poder, segundo Foucault, não deve ser apenas descendente, mas ascendente, visando rastrear a maneira pela qual as táticas, técnicas, procedimentos e instrumentos locais são apropriados, transformados e utilizados por dinâmicas mais amplas e globais. Neste caso, não se trata de indagar de que maneira grupos minoritários ou comunidades locais assimilam uma política linguística estatal, mas a maneira como as esferas reguladoras utilizam, transformam ou se apropriam de uma dinâmica local da relação entre os sujeitos e as línguas, pois isto passa a ter um valor político ou econômico. É o que se nota, por exemplo, na tese defendida por Dor (2004) de que, diferentemente de uma tendência à presença do inglês como língua franca na internet, o que se tem cada vez mais é o crescimento do multilinguismo na rede. Isso, evidentemente, não por motivos democráticos, mas sim porque o multilinguismo seria mais economicamente produtivo do que a presença maciça de uma língua (o inglês). O autor justifica essa tese pelo valor econômico e o interesse de empresas em, por exemplo, acessar os usuários em sua língua vernacular ao invés do inglês ou outra língua, pois esta seria uma maneira de ganhar maior confiança e credibilidade, uma vez que pesquisas do perfil dos consumidores (DOR, 2004) mostram que em geral eles tendem a preferir sites de compras em sua própria língua, por questões de confiabilidade. Assim, as línguas assumem o papel de "ferramentas mercantilizadas de comunicação" (commodified tools of communication) (DOR, 2004, p.98), em torno das quais uma política linguística digital passa a funcionar. Este interesse por criar uma aproximação com o consumidor através de sua língua tem motivado uma série de ações, conduzidas por diferentes agentes da economia global, como a elaboração de softwares de tradução automática e a construção de bancos de dados linguísticos. E os efeitos do processo de variação e mudança sofrido pelas línguas passam, também, a incorporar um valor econômico: 
[...] nós já testemunhamos a emergência global de novos padrões de uso linguístico, de padronização, manutenção e variabilidade - padrões que acima de tudo atendem às necessidades do mercado de consumidores global em evolução. ${ }^{16}$ (DOR, 2004, p.98).

(v) Na esteira do item anterior, o poder não opera produzindo ideologias, como a ideologia do liberalismo, a ideologia da democracia na internet ou a ideologia do multilinguismo liberal, entre outras. O que há, segundo Foucault, são procedimentos, técnicas e práticas que visam à formação de saberes. Exemplificando, as práticas de observação, exame, registro, inquérito, sistematização, classificação, rotulação, entre outras, são constitutivas da produção de discursos com efeitos de verdade: "[...] o poder, para exercer-se nestes mecanismos sutis, é obrigado a formar, organizar e por em circulação um saber, ou melhor, aparelhos de saber que não são construções ideológicas." (FOUCAULT, 1999a, p.104). No contexto digital, tais aparelhos, procedimentos e técnicas de poder-saber são amplamente utilizados pelo Google, o que se evidencia pela sua capacidade de registro contínuo e detalhado de dados, percursos, relações e informações, sendo que todos eles são transformados em saberes sobre os sujeitos, os desejos, o consumo, os Estados e as relações. Muitos desses saberes são apropriados por empresas, transformados em produtos e devolvidos aos usuários na forma de publicidade personalizada (BUZATO; SEVERO, 2010). Nota-se, no contexto linguístico, que a apropriação das práticas dos sujeitos na internet pelos agentes da economia global - entre eles, o Google - é tomado como base de uma política linguística gerida por esses mesmos agentes. Exemplificando, o Google Tradutor, ao oferecer sugestões, baseadas em estatísticas, de tradução em mais de 40 línguas, também se apropria das indicações linguísticas sobre as traduções feitas pelos usuários, os quais compartilham diferentes níveis de competência linguística em diferentes línguas. A técnica estatística utilizada pelo Google Tradutor é um exemplo de procedimento de poder para fins de produção de um saber sobre as línguas, ou melhor, sobre a correlação entre línguas. No site do Google Tradutor, em perguntas frequentes, encontra-se a seguinte descrição do procedimento:

Alimentamos o computador com bilhões de palavras de texto, tanto texto monolíngue no idioma de destino como texto alinhado com exemplos de traduções entre os idiomas feitas por pessoas. Em seguida, aplicamos técnicas de aprendizado baseadas em estatísticas para criar um modelo de tradução. Atingimos ótimos resultados nas avaliações de pesquisas. (GOOGLE, 2012).

16 "[...] we already witness the global emergence of novel patterns of linguistic usage, standardization, maintenance, and variability - patterns that more than anything else meet the needs of the evolving global consumers market." 
Ao entrar na página do Google Tradutor, visualiza-se uma caixa destinada à digitação do texto em língua fonte, e outra ao texto da língua traduzida. Nesta segunda caixa, aparecem no canto direito inferior três ícones, entre os quais está "avaliar a tradução", cujas opções fornecidas ao usuário são "ajudou, não ajudou, ofensivo". Um outro exemplo de serviço de tradução oferecido pelo Google são os links com a informação "traduzir esta página" que aparecem em algumas páginas da internet listadas pelo sistema de busca do Google. Ao entrar na página, é possível selecionar o texto traduzido e clicar com o botão esquerdo do mouse em "Sugira uma tradução melhor". Em ambos os casos, o usuário deve fornecer ao software de tradução o seu conhecimento e avaliação linguísticos, os quais são transformados em saber utilizado pelo Google para gerir a relação semântica entre as línguas na internet e a circulação dos sujeitos por diferentes sites mediante o oferecimento da tradução como recurso mediador entre o usuário e a informação/ produto/relação desejada.

Um outro exemplo de procedimento de poder para a produção de saber utilizado pelo Google foi o projeto GOOG-411, iniciado em 2007 e finalizado em 2012, que visou ao levantamento de amostras de fala do inglês americano e canadense através do oferecimento de um serviço gratuito que colocava o usuário em contato com empresas através da correlação, feita pelo Google, entre o reconhecimento de voz e a pesquisa na web: bastava ao usuário fornecer oralmente o nome da cidade, do estado e a empresa de seu interesse, que o sistema repassava a ligação local. O preço pago por este serviço seria "apenas" a gravação da voz do usuário. Com isso, o Google pretendia montar um vasto banco de dados e investir em tecnologia de reconhecimento de voz.

(vi) Uma sexta característica atribuída ao funcionamento do poder por Foucault diz respeito à resistência: todo ponto de aplicação do poder produz, como efeito potencial, a possibilidade de resistência, estando esta inscrita no interior da dinâmica das relações de poder e não no seu exterior. Logo, se o poder é plural, difuso e dinâmico, as resistências também o são: "[...] a pulverização dos pontos de resistência atravessa as estratificações sociais e as unidades individuais." (FOUCAULT, 1999b, p.92). Aplicada ao escopo da política e planejamento linguísticos, a resistência se materializa em diferentes dimensões e níveis. Para exemplificar, toma-se o caso da globalização e o discurso correlato de uma nova colonização ideológica pela imposição e circulação maciça do inglês pela internet, argumento que é reforçado por estatísticas que confirmam a predominância da língua no ambiente digital, como o "Top Ten Languages Internet Stats" da internet, que atribuiu ao inglês mais de 536 milhões de usuários em 2010, contra cerca de 444 milhões para a língua chinesa, e 153.3 milhões para o espanhol, a terceira língua mais usada. Contudo, na contramão dos discursos que advogam o perigo do monolinguismo na rede, defende-se que a diversidade (linguística e discursiva) encontra formas de resistência. Considerando a língua inglesa na 
internet, evidentemente, ela não é homogênea, mas se caracteriza por uma série de variedades estratificadas tanto entre localidades geopolíticas (inglês americano, britânico, australiano), como entre os graus de proficiência dos falantes dessas línguas (língua nativa, segunda língua, língua estrangeira), além das diferentes finalidades do uso do inglês.

Essa heterogeneidade de falantes, contextos e finalidades em torno do inglês acaba, por fim, produzindo efeitos de variação, hibridização e estilização da língua desde o nível fonético-fonológico até o textual e discursivo. Assim, a ilusão da homogeneidade do inglês na internet é estremecida pela proposição, segundo Rajagopalan (2005), de que a globalização tem favorecido o surgimento do World English, uma nova língua sem relação direta e única com alguma cultura hegemônica (anglo-saxã ou americana). Trata-se de uma língua hibridizada linguística, cultural e politicamente, fenômeno que tanto potencializa a possibilidade de resistência de grupos marginalizados, como afrouxa o domínio de grupos hegemônicos. Com isso, no contexto de aprendizagem do inglês como língua estrangeira, o papel do professor seria o de auxiliar o aprendiz "[...] a dominar a língua estrangeira, em vez de ser dominado por ela." (RAJAGOPALAN, 2005, p.154), em que não se nega a dimensão global do Inglês, mas visa a munir os alunos de uma postura crítica e política em relação ao uso da língua. Sobre a estratificação do inglês e a emergência e circulação de outras línguas na Web, Graddol (1997) elenca algumas de suas motivações: uma economia global dinâmica, a ascensão de outros mercados culturais e intelectuais, o avanço tecnológico de outras culturas, a valorização social, econômica e cultural de outras línguas e do bimultilinguismo, entre outros.

A circulação de uma variedade de línguas não garante, por si só, a circulação de visões de mundo diversas, embora a língua possa ser tomada, entre outros elementos, como bandeira de resistência de grupos subalternizados e colonizados, como é o caso de algumas etnias indígenas que usam os discursos em defesa da língua indígena como estratégia de resistência ao apagamento e silenciamento impostos aos indígenas pela colonização (OLIVEIRA; PINTO, 2011). Por outro lado, o monolinguismo também não pode ser tomado como sinônimo de homogeneização cultural e social. A possibilidade de circulação de discursos plurais, que carregam diferentes visões e formas de ser/estar no mundo, em uma "mesma língua" funciona também como resistência à colonização discursiva e cultural. É o caso da Literatura Indígena, em que os escritores indígenas utilizam politicamente a escrita em língua portuguesa para materializar os discursos e valores indígenas, inclusive para fazer a memória, tradicionalmente atualizada por práticas orais, ecoar e se fixar pela escrita ocidental. Nas palavras do escritor indígena Daniel Munduruku (2008), 
[...] é preciso se tornar conhecido. É preciso escrever - mesmo com tintas do sangue - a história que foi tantas vezes negada. A escrita é uma técnica. É preciso dominar esta técnica com perfeição para poder utilizá-la a favor da gente indígena.

Para finalizar esta seção, a abordagem foucaultiana do poder como inspiração para se pensar tanto os saberes de política e planejamento linguísticos, como as práticas e discursos sobre a relação entre as línguas, entre as línguas e os sujeitos, as línguas e a tecnologia, e as línguas e uma dada geopolítica visa, tão somente, a

[...] orientar para uma concepção de poder que substitua o privilégio da lei pelo ponto de vista do objetivo, o privilégio da interdição pelo ponto de vista da eficácia tática, o privilégio da soberania pela análise de um campo múltiplo e móvel de correlações de força, onde se produzem efeitos globais, mas nunca totalmente estáveis, de dominação. (FOUCAULT, 1999b, p.97).

\section{Palavras finais}

Este texto teve como objetivo discorrer de forma reflexiva sobre as noções de poder e de política inscritas no campo de saber da Política e Planejamento Linguísticos. Tal campo é multifacetado e heterogêneo, o que ilustra a natureza dinâmica e complexa do poder em relação ao funcionamento e circulação das línguas seja em contexto local, seja em contexto amplo (nacional ou internacional). Mais especificamente sobre o multilinguismo na Web 2.0, fica evidente que a tecnologia desempenha um papel político, uma vez que propicia a viabilização, 0 controle, a circulação e o favorecimento de certas línguas, em detrimento de outras, na rede. Isso porque grande parte dessa existência depende do investimento em softwares usados para gerar conteúdos, softwares de tradução, teclados com grafias específicas, acessibilidade, entre outros, que possibilitam a existência prática dessas línguas na web e o acesso de grupos marginalizados à tecnologia digital. Ademais, o favorecimento da existência das línguas, seja na web, seja em contextos variados, por meios de políticas estatais não garante, por si só, a sua ampla circulação, como se evidenciou em relação ao multilinguismo sul-africano. Disso depreende-se a importância de uma articulação, por um lado, entre política e planejamento linguísticos e, por outro, entre as instâncias oficiais/ legitimadoras e a realidade local dos sujeitos efetivamente envolvidos, de forma que se reconheça "[...] a agência das comunidades subalternizadas para negociarem políticas linguísticas de forma criativa e crítica que transcenda as construções limitadas formuladas seja para varrer cinicamente, seja para indevidamente romantizar, os direitos lingüísticos."17 (CANAGARAJAH, 2005, p.418).

17 " [...] the agency of subaltern communities to negotiate language politics in creative and critical ways that transcend the limited constructs formulated to either cynically sweep aside or unduly romanticize language rights." 
Defende-se, a partir dos trabalhos de Foucault, que a dinâmica das relações de poder não é uma variável exterior ao funcionamento das línguas, mas seu próprio motor de constituição e circulação. A compreensão das sutilezas desta dinâmica possibilita tanto uma ampliação dos campos de intervenção da política e planejamento linguísticos, como um olhar crítico sobre certas aplicações e conceitos que, no final das contas, visam a reproduzir o status quo ou uma certa política autoritária e legitimadora de grupos de prestígio. Nota-se que a ampliação da compreensão dos conceitos de política e planejamento linguísticos produz como efeito um estremecimento de seu vínculo apenas à esfera acadêmica. Se as relações de poder permeiam toda a rede social, então os sujeitos locais, as práticas, as crenças, as tecnologias, entre outros, são constitutivos de uma política linguística real e não apenas produzida e imposta verticalmente. Tratase, portanto, de duas formas de apreensão e compreensão das relações entre as línguas, as línguas e os sujeitos, as línguas e a tecnologia, e as línguas e o Estado: uma que se mantém nos limites disciplinares e outra que busca uma intervenção propriamente público-política, que não pretende a manutenção de privilégios para certos grupos ou discursos e, tampouco, o apagamento das vozes sociais ou da pluralidade discursiva. Acredita-se que a promoção de discursos sobre a diversidade linguística não garante, necessariamente, o diálogo no plural, dado que o lugar do diálogo e da pluralidade não é na língua-estrutura, mas na língua-discurso, embora ambos estejam mutuamente implicados. Defende-se, por fim, que as práticas de promoção do multilinguismo devem ser acompanhadas da promoção da diversidade discursiva, caso contrário, o multilinguismo acompanhado de monologismo discursivo fica fadado ao fracasso.

SEVERO, C. G. Language policy(ies) and power issues. Alfa, São Paulo, v.57, n.2, p.451-473, 2013.

- ABSTRACT: The paper presents and discusses the concepts of power and politics in the field of knowledge called "Language Policy". In order to do so, we initially present and discuss the heterogeneity and complexity of the field considering the concepts of Language Policy and Language Planning. Then we present the genealogical works of the French philosopher Michel Foucault on the relationship among power, knowledge and politics. For the purpose of critical discussion, the article presents a series of cases, both actual and potential ones, of application and intervention of the field of Language Policy, aiming both to discuss the notion of power in concepts and methodologies used by this field of study and to propose an expansion of the locus of intervention of the discipline, considering the theoretical contributions of Michel Foucault on the dynamics of power relations applied to the relationship between languages, languages and subjects, languages and technology, and language and geopolitics.

- KEYWORDS: Language Policy. Language planning. Power. Knowledge. Language. Subjects. Internet. 


\section{REFERÊNCIAS}

ARENDT, H. A condição humana. Tradução de Roberto Raposo. 10.ed. Rio de Janeiro: Forense Universitária, 2005.

BAKER, C. Language planning: a grounded approach. In: DEWAELE, J.-M.; HOUSEN, A.; WEI, L. (Org.). Bilingualism: beyond basic principles. Clevedon: Multilingual Matters Ltd, 2003. p.88-111.

BARROS, M. C. D. M. A relação entre manuscritos e impressos em tupi como forma de estudo da política lingüística jesuítica no século XVIII na Amazônia. Revista Letras, Curitiba, n.61, especial, p.125-152, 2003.

BIANCO, J. L. Language planning as applied linguistics. In: DAVIES, A.; ELDER, C. (Org.). The handbook of applied linguistics. Oxford: Blackwell Publishing, 2004. p.738-762.

BIJKER, W. E. Why and how technology matters. In: GOODIN, R. E.; TILLY, C. Oxford handbook of contextual political analysis. Oxford: Oxford University Press, 2006. p.681-706. Disponível em: <http://www.fdcw.unimaas.nl/staff/files/ users/148/Bijker\%20PoliticsOxfordHndb\%202006.pdf>. Acesso em: 28 ago. 2012.

BLOMMAERT, J. Supervernaculars and their dialects. Dutch Journal of Applied Linguistics, Amsterdã, v.1, n.1, p.1-14, 2012.

BONACINA-PUGH, F. Researching 'practiced language policies': insights from conversation analysis. Language Policy, Dordrecht, v.11, n.3, p.213-234, 2012.

BUZATO, M. K.; SEVERO, C. G. Apontamentos para uma análise do poder em práticas discursivas e não discursivas na web 2.0. In: ENCONTRO DO CELSUS, 9., 2010, Palhoça. Anais... Palhoça: Ed. da UNISUL, 2010. Disponível em: <http:// www.celsul.org.br/Encontros/09/artigos/Marcelo\%20Buzato.pdf>. Acesso em: 12 jun. 2012.

CALVET, L.-J. As políticas linguísticas. Tradução de Isabel de Oliveira Duarte, Jonas Tenfen e Marcos Bagno. São Paulo: Parábola, 2007.

CANAGARAJAH,A. S. Dilemmas in planning English/vernacular relations in postcolonial communities. Journal of Sociolinguistics, Chichester, v.9, n.3, p.418-447, 2005. Disponível em: <http://www.personal.psu.edu/asc16/pdf/05_josl005.pdf>. Acesso em: 20 jul. 2012.

COBARRUBIAS, J.; FISHMAN, J. A. (Org.). Progress in language planning: international perspectives. Berlin: Mouton, 1983.

COOPER, R. L. Language planning and social change. Cambridge: Cambridge University Press, 1989. 
DANET, B.; HERRING, S. C. (Org.). The multilingual internet, language, culture, and communication online. Oxford: Oxford Scholarship Online, 2007.

DOR, D. From englishization to imposed multilingualism: globalization, the internet, and the political economy of the linguistic code. Public Culture, Durham, v.16, n.1, p.97-118, 2004.

FERGUSON, C. Language planning and language change. In: COBARRUBIAS, J;; FISHMAN, J. A. (Org.). Progress in language planning. international perspectives. Nova York: Mouton Publishers: 1983. p.29-40.

FISHMAN, J. A.; FERGUSON, C. A.; DASGUPTA, J. (Org.). Language problems of developing nations. New York: Wiley \& Sons, 1968.

FOUCAULT, M. Soberania e disciplina. Tradução de Roberto Machado. In: Microfísica do poder. Rio de Janeiro: Graal, 1999a. p.179-192.

. A história da sexualidade I: a vontade de saber. Tradução de Maria Thereza Albuquerque. Rio de Janeiro: Graal, 1999b.

. A ordem do discurso. Tradução de Laura Fraga de Almeida Sampaio. São Paulo: Loyola, 1996.

O sujeito e o poder. In: RABINOW, P.; DREYFUS, H. Michel Foucault:uma trajetória filosófica: para além do estruturalismo e da hermenêutica. Tradução de Vera Porto Carrero. Rio de Janeiro: Universitária, 1995. p.231-252.

GADELII, K. E. Language planning: theory and practice: evaluation of language planning cases worldwide. Paris: UNESCO, 1999.

GOOGLE. Disponível em: <https://translate.google.com.br/?hl=pt-BR\&tab=wT> . Acesso em: 02 ago. 2012.

GRADDOL, D. The future of English? a guide to forecasting the popularity of the English language in the 21st Century. Londres: Conselho Britânico do Reino Unido, 1997. Disponível em: <http://www.britishcouncil.org/learning-elt-future. pdf >. Acesso em: 31 jul. 2012.

HAUGEN, E. Language conflict and language planning: the case of modern Norwegian. Cambridge: Cambridge University Press, 1966.

. Language planning in modern Norway. Scandinavian Studies, Dinamarca, v.33, n.2, p.68-81, 1961.

HILL, L. B. Language and status: on the limits of language planning. Stellenbosch Papers in Linguistics, Matieland, v.39, p.41-58, 2010.

KAPLAN, R. B.; BALDAUF. R. B. Language planning from practice to theory. Clevedon: Multilingual Matters, 1997. 
KLOSS, H. "Abstand languages" and "Ausbau languages". Journal of Anthropological Linguistics, Nova York, v.9, n.7, p.29-41, 1967.

MAKONI, S.; MEINHOF, U. Linguística aplicada na África: desconstruindo a noção de língua. In: LOPES, L. P. de M. (Org.). Por uma linguística aplicada indisciplinar. São Paulo: Parábola, 2006. p.191-213.

MANLEY, M. S. Quechua language attitudes and maintenance in Cuzco, Peru. Language Policy, Nova York, v.7, p.323-344, 2008.

MUNDURUKU, D. Literatura indígena e o tênue fio entre escrita e oralidade. Overmundo, 2008. Disponível em: <http://www.overmundo.com.br/overblog/ literatura-indigena>. Acesso em: 01 ago. 2012.

OLIVEIRA, E. A.; PINTO, J. P. Linguajamentos e contra-hegemonias epistêmicas sobre linguagem em produções escritas indígenas. Linguagem em (dis)curso, Tubarão, v.11, n.2, p.311-335, 2011. Disponível em: <http://www.scielo.br/scielo. php?script=sci_arttext\&pid=S1518-76322011000200006\&lng=en\&nrm=iso > . Acesso em: 31 jul. 2012

RAJAGOPALAN, K. A geopolítica da língua inglesa e seus reflexos no Brasil. In: LACOSTE, Y.; RAJAGOPALAN, K. (Org.). A geopolítica do inglês. São Paulo: Parábola, 2005. p.135-158.

SEVERO, C. G. Questões de língua, identidade e poder: hibridismos em Timor Leste. Revista Brasileira de Linguística Aplicada, Belo Horizonte, v.11, p.95-113, 2011a. . Línguas e discursos: heterogeneidade linguístico-discursiva e poder em Angola. Veredas, Lisboa, v.15, p.19-46, 2011b.

WEBB, V. Multilingualism in South Africa: the challenge to below. Language matters: studies in the languages of Africa, Londres, v.40, n.2, p.190-204, 2009.

Recebido em agosto de 2012

Aprovado em novembro de 2012 